University of Wollongong

Research Online

Faculty of Engineering and Information

Faculty of Engineering and Information

Sciences - Papers: Part B

Sciences

2017

\title{
Influence of geogrid on the drying shrinkage performance of concrete pavements
}

\author{
Abbas Sahib Abd-Ali Al-Hedad \\ University of Wollongong, asaa774@uowmail.edu.au \\ Ebony Bambridge \\ University of Wollongong, ekb960@uowmail.edu.au \\ Muhammad N. S Hadi \\ University of Wollongong, mhadi@uow.edu.au
}

Follow this and additional works at: https://ro.uow.edu.au/eispapers1

Part of the Engineering Commons, and the Science and Technology Studies Commons 


\title{
Influence of geogrid on the drying shrinkage performance of concrete pavements
}

\begin{abstract}
The aim of this study is to investigate the effect of geogrid on the drying shrinkage behaviour of concrete pavements. For this purpose, two categories of concrete specimens were prepared and tested by drying them within the controlled environmental conditions, for 56 days. The first category of specimens included casting and testing nine concrete prism specimens having dimensions of $75 \times 75 \times 280 \mathrm{~mm}$. These specimens were divided into three groups. The first group included three unreinforced concrete prism specimens and taken as references. The second group consisted of three concrete prism specimens reinforced with a single biaxial geogrid layer located at $20 \mathrm{~mm}$ from the top of specimen. The last three specimens (third group) were reinforced with a biaxial geogrid layer placed at $37.5 \mathrm{~mm}$ from the top of specimen. The second category of specimens, which was suggested in this study to simulate the behaviour of concrete pavements, consisted of preparing and testing six concrete slab specimens. They had dimensions of $30 \times 280 \times 280 \mathrm{~mm}$. The specimens of this category were divided into two groups. The first group included three unreinforced concrete slab specimens (References). The second group included three concrete slab specimens reinforced with a single biaxial geogrid layer placed at $15 \mathrm{~mm}$ from the top of specimen. The changes in the length of the prisms and the changes in the area of the slabs were measured and evaluated. Test results obtained illustrate that, under the controlled drying conditions, the geogrid can slightly reduce the drying shrinkage strains of the concrete pavements.
\end{abstract}

\section{Keywords}

concrete, pavements, geogrid, performance, influence, shrinkage, drying

Disciplines

Engineering | Science and Technology Studies

\section{Publication Details}

Al-Hedad, A., Bambridge, E. \& Hadi, M. N. S. (2017). Influence of geogrid on the drying shrinkage performance of concrete pavements. Construction and Building Materials, 146 165-174. 


\title{
Influence of Geogrid on the Drying Shrinkage Performance of
}

\author{
Concrete Pavements
}

\author{
Abbas S. A. Al-Hedad ${ }^{1}$, Ebony Bambridge ${ }^{2}$, and Muhammad N. S. Hadi ${ }^{3}$ \\ ${ }^{1}$ PhD Candidate, School of CME Engineering, University. of Wollongong, Wollongong, NSW \\ 2522, Australia.E-mail: asaa774@uowmail.edu.au \\ ${ }^{2}$ School of CME Engineering, University. of Wollongong, Wollongong, NSW 2522, Australia. \\ E-mail:ekb960@uowmail.edu.au \\ ${ }^{3}$ Associate Professor, School of CME Engineering, University. of Wollongong, Wollongong, \\ NSW 2522, Australia (corresponding author).E-mail: mhadi@uow.edu.au
}

\section{Abstract}

The aim of this study is to investigate the effect of geogrid on the drying shrinkage behaviour of concrete pavements. For this purpose, two categories of concrete specimens were prepared and tested by drying them within the controlled environmental conditions, for 56 days. The first category of specimens included casting and testing nine concrete prism specimens having dimensions of $75 \times 75 \times 280 \mathrm{~mm}$. These specimens were divided into three groups. The first group included three unreinforced concrete prism specimens and taken as references. The second group consisted of three concrete prism specimens reinforced with a single biaxial geogrid layer located at $20 \mathrm{~mm}$ from the top of specimen. The last three specimens (third group) were reinforced with a biaxial geogrid layer placed at $37.5 \mathrm{~mm}$ from the top of specimen. The second category of specimens, which was suggested in this study to simulate the behaviour of concrete pavements, consisted of preparing and testing six concrete slab specimens. They had dimensions of $30 \times 280 \times 280 \mathrm{~mm}$. The specimens of this category were divided into two groups. The first group included three unreinforced concrete slab specimens (References). The second group included three concrete slab specimens reinforced with a 
single biaxial geogrid layer placed at $15 \mathrm{~mm}$ from the top of specimen. The changes in the length of the prisms and the changes in the area of the slabs were measured and evaluated. Test results obtained illustrate that, under the controlled drying conditions, the geogrid can slightly reduce the drying shrinkage strains of the concrete pavements.

Author keywords: Concrete prism specimens; Concrete slab specimens; Controlled drying conditions; Biaxial geogrid; Drying shrinkage strains

\section{Introduction}

The early age behaviour of Portland cement concrete (PCC) pavements is significantly influenced by weather conditions. This is because the PCC pavements possess a large surface area exposed to the effect of climate changes. Temperature and relative humidity have a combined effect on the PCC pavements, especially in the drier environments or when the curing conditions of concrete being inadequate. This leads to an increase in the rate of the evaporation of concrete mix water, and therefore, the PCC pavement would be more likely to shrink.

High temperature of the concrete surface makes the concrete to lose the moisture gradually through the surface. The pore water moves towards the surface through the pore network [1]. This results in variable moisture content in space and time. In addition, the value of temperature between the top and bottom of the slab will be different. When the rate of evaporation exceeds the rate of pore water movement towards the surface, the concrete will start to shrink, which is called the drying shrinkage.

The drying shrinkage can be defined as the reduction in the concrete volume due to the influence of environmental conditions [2]. This reduction may be considered a critical situation for concrete pavements and may significantly affect the performance and lifetime of 
concrete roads. Sometimes the drying shrinkage leads to a generation of excessive thermal strains and stresses in the concrete, in turn, mostly leading to cracking of concrete pavements. The concrete cracking may result in reducing the effective design stress used in the pavements by up to $50 \%[1]$.

Several studies were conducted to examine the effect of temperature and relative humidity on the behaviour of concrete pavements during the early-age of their service life. For example, Asbahan and Vandenbossche [3], Zhang et al. [4], and Kim et al. [5] investigated the response of jointed plain concrete pavement subjected to environmental effects. They concluded that the slab curvature which resulted from the effect of temperature and relative humidity influences the locations and magnitude of the critical stresses in the concrete pavement. In turn, the performance of the pavement for the long term will be affected. The authors also reported that the slab curvature, which resulted from the daily fluctuations of temperature or from reversible drying shrinkage, is not significantly reduced when using dowel and tie bars.

Zhang et al. [6] theoretically studied the drying shrinkage behaviour of normal strength concrete and developed a micromechanical model using the finite element method. The model was derived based on the capillary tension created in the capillary pores of the concrete and considered the interior humidity as a driving parameter. The authors recommended that the model can be used to predict the shrinkage-induced strains of concrete at a different time and different positions. In general, these studies emphasized that the environmental loads can be critical factors in the deformation of concrete pavements and, thus, on the long-term performance of the pavement.

Several previous studies tried to address the effect of shrinkage deformation on the concrete using different reinforcement materials. Shao and Mirmiran [7] investigated the role of fibre- 
71 reinforced polymer (FRP) grids and rods on the drying shrinkage deformation of concrete

72 pavements. They illustrated that the FRP grids could be used instead of steel reinforcement in restraining the shrinkage deformation and could be placed closer to the surface. But the cost of construction using the FRP reinforcement is in the rise.

Fibre reinforcement such as steel, polypropylene and synthetic fibres was used to restrain the shrinkage deformation of concrete. Jafarifar et al. [1]; and Ahamed et al. [8] studied the drying shrinkage behaviour of concrete pavements reinforced with recycled steel fibres. They concluded that the shrinkage strains of concrete reinforced with the steel fibres was lower than that of plain mixes. Using fibres to mitigate the shrinkage deformation of concrete pavements can be source of problems when mixing the concrete or in the workability of the concrete, especially at the high fibre percentages.

Bentz and Weiss [9], Güneyisi et al. [10]; Wei et al. [11]; and Kim and Chun [12] investigated the effect of pre-wetted lightweight fine and coarse aggregates as an internal curing technique on the autogenous and drying shrinkage behaviour of concrete. Although the use of this technique could mitigate the shrinkage deformation of cured concrete, the rate of shrinkage development was faster than the control concrete. Also, the early strength and the modulus of elasticity of the concrete were reduced.

Geogrid, which is basically used to strengthen the weak soils, has been recently utilised as a reinforcement layer for Portland cement concrete elements. This is because they have several structural characteristics such as a high tensile strength and corrosion resistance [13-15]. Siva and Agarwal [16-18] and Wang et al. [19] investigated the performance of concrete prismatic and cylindrical specimens strengthened with the geogrid. These investigations demonstrated that the flexural, compressive, and shear strength of concrete could be improved, as well as, 
94 the cracking resistance of concrete specimens could be increased. However, using geogrid 95 products for reinforcing the Portland cement concrete elements are a new direction. So, 96 additional research studies to find out more benefits for geogrid applications are required. In 97 this study, the biaxial geogrid was used as a restraining layer of drying shrinkage for concrete 98 prism and slab specimens.

\section{Objective of study}

100 The purpose of this study is to investigate the effect of geogrid on the drying shrinkage

101 behaviour of concrete pavements by drying the specimens within controlled environmental 102 conditions, at a temperature of $23 \pm 3^{\circ} \mathrm{C}$ and Relative Humidity (RH) of $60 \pm 10 \%$. Two 103 categories of normal strength concrete specimens were prepared and tested. They were prism 104 and slab specimens having dimensions of $75 \times 75 \times 280 \mathrm{~mm}$ and $30 \times 280 \times 280 \mathrm{~mm}$, 105 respectively.

\section{Properties of biaxial geogrid}

107 The biaxial geogrid was used as a drying shrinkage restraining layer. This is because the 108 arrangement of biaxial geogrid ribs and roughness of nodes' surface can provide an 109 appropriate bond between the geogrid layer and the surrounding concrete [20].

110 The biaxial geogrid used in this study is manufactured from polypropylene composite 111 materials [21]. It had square openings with inner dimensions of $38 \times 38 \mathrm{~mm}$, as shown in 112 Figure 1. The ribs of the biaxial geogrid used were interconnected together at one point called

113 node (junction). They had a cross section area of $2 \times 3 \mathrm{~mm}$ measured by a digital vernier 114 calliper gauge. 
115 The mechanical properties of the biaxial geogrid were determined using the standard of

116 American Society for Testing and Materials (ASTM) D6637/D6637M-15 [22]. The Single

117 Geogrid Rib (SGR) sample was adopted in this test. In total, five SGRs were prepared and

118 tested under a tensile force at a rate of $8 \mathrm{~mm} / \mathrm{min}$, as shown in Fig. 2(a). The instron tensile

119 testing machine that has a capacity of $10000 \mathrm{~N}$ was used to test the geogrid samples. All tests

120 were conducted at the High Bay Laboratory of the School of Civil, Mining and

121 Environmental Engineering, University of Wollongong (UOW), Australia.

122 Each biaxial geogrid sample was selected from the batch and prepared according to the requirements of ASTM D6637/D6637M-15 [22]. All samples consisted of four junctions in order to provide the minimum required length and were free from any surface defects. The average length of geogrid samples, which is defined as the length of geogrid rib measured

126 between the ends of the testing machine clamps and called initial gauge length, was $200 \mathrm{~mm}$, 127 as shown in Fig. 2(b). The testing was stopped when the geogrid rib was ruptured (Fig. 2(c)).

128 Table 1 lists the physical and mechanical properties of the tested biaxial geogrid samples. The 129 tensile strength of the samples ranged between $1222 \mathrm{~N}$ to $1467 \mathrm{~N}$ with the corresponding 130 elongation of 57 to $109 \mathrm{~mm}$. These results satisfy with the requirements of ASTM

131 D6637/D6637M-15 [22]. The average tensile strength and elongation of samples were $1341 \mathrm{~N}$ 132 and $81 \mathrm{~mm}$, respectively. Fig. 3 shows the tensile strength versus the corresponding strains of 133 the five biaxial geogrid samples.

134 A wide tolerance before accept or reject the test results of geosynthetic products (geogrid is 135 one of these products) is permitted by ASTM D6637/D6637M-15 [22]. This is because these 136 products are extensively affected by environmental conditions of the laboratory and 137 characteristics of tested geogrid samples. However, from Figure 3, it can be seen that there are 
138 differences in the results of the tensile strengths and elongations of the biaxial geogrid

139 samples. These differences are acceptable according to the limitations of ASTM 140 D6637/D6637M-15 [22].

\section{4. Experimental program}

\subsection{Preparation of specimens}

143 Table 2 provides details of the experimental program adopted in this study. Two categories of

144 concrete specimens were prepared and tested. The first category of specimens that was

145 prepared according to Australian Standards (AS) 1012.8.4 [23] included casting and testing

146 nine concrete prism specimens with dimensions of $75 \times 75 \times 280 \mathrm{~mm}$. These specimens were

147 divided into three groups. The first group, which is labelled Group UP, included three

148 unreinforced concrete prism specimens and taken as references. The second group consisted

149 of three concrete prism specimens reinforced with a single biaxial geogrid layer located at 20

$150 \mathrm{~mm}$ from the top of specimen and is named Group GP20. The last three of concrete prism

151 specimens were reinforced with a biaxial geogrid layer placed at $37.5 \mathrm{~mm}$ from the top of

152 specimen (middle of thickness) and is labelled Group GP37.5.

153 The second category of specimens, which is suggested in this study to mimic as much as

154 possible the behaviour of concrete pavements, consisted of preparing and testing six concrete

155 slab specimens. They had dimensions of $30 \times 280 \times 280 \mathrm{~mm}$, as listed in Table 2 . The

156 specimens of this category were divided into two groups. The first group included three

157 unreinforced concrete slab specimens (References) and is labelled Group US. The second 158 group included three concrete slab specimens reinforced with a single biaxial geogrid layer 
159 placed at $15 \mathrm{~mm}$ from the top of specimen and is named Group GS. Fig. 4 and 5 show more

160 details of the concrete prism and slab specimens.

161 The $30 \mathrm{~mm}$ thickness of slab specimens was selected in this study to minimize the wide 162 variation of the temperature and moisture gradients the slab surfaces and the middle of 163 thickness of the slab, which are exposed to the environmental conditions. Thus, the readings 164 of the drying shrinkage collected from the gauge studs, which were located at the middle of 165 the slab depth, can be considered as the average of results of the drying shrinkage for the 166 whole slab specimen. In addition, this value of the thickness allows achieving the movement 167 and evaporation of moisture from the slab in one direction (from the top and bottom of the 168 slab surfaces only). This case simulates to the movement and evaporation of moisture for the 169 concrete pavements [1].

\subsection{Preparation of moulds}

171 Nine standard metal moulds were used for moulding the prism specimens of the first

172 category, as shown in Fig. 6. They possessed inner dimensions of $75 \times 75 \times 280 \mathrm{~mm}$. For 173 each prism mould, two steel slides having dimensions of $1.5 \times 75 \times 75 \mathrm{~mm}$ were cut and put 174 inside of the moulds to achieve exactly an inner length of $280 \mathrm{~mm}$. In addition, gauge studs 175 made from stainless steel were used to be the reference points during collecting the test 176 readings. The dimensions of studs satisfied the requirements of AS 1012.13:2015 [24] were

$17722.5 \pm 0.1 \mathrm{~mm}$ of length and a diameter of $6 \mathrm{~mm}$. Two gauge studs were screwed into the 178 gauge stud holder, one at each of the end of the prism specimens. While, four gauge studs 179 were screwed into the gauge stud holder at each side of the slab specimens. 
180 For moulding the concrete specimens of the second category, slab specimens, six timber 181 moulds were designed and prepared in this study, as shown in Fig. 7. They possessed inner 182 dimensions of $30 \times 280 \times 280 \mathrm{~mm}$. The walls of these moulds were fixed with the base using

18316 screws. The inside of the moulds was covered with a $0.125 \mathrm{~mm}$ thick Vinyl sheet to keep 184 the concrete mix water and to reduce the friction force between the slab and the timber 185 moulds.

\subsection{Setup of specimens}

187 The dimensions of the biaxial geogrid layer embedded in the concrete specimens were lower 188 than the entire dimensions of the specimens by about $15 \mathrm{~mm}$ for prism specimens and $40 \mathrm{~mm}$

189 for slab specimens, as shown in Fig. 8. This is because the temperature and RH gradients at 190 the edges of concrete specimens are often regular. Thus, the variation in the temperature 191 between the top and bottom of the concrete surface can be negligible [25].

192 To fix the geogrid reinforcement layer during the pouring of concrete at the required level of 193 the slab specimens, a small wire having a diameter of $0.05 \mathrm{~mm}$ was used at each corner of the 194 slab and removed after 24 hours from the casting.

195 All specimens were cast on the same day using ready-mixed concrete, which was supplied by 196 Hanson Company, Australia [26]. The proportion of concrete ingredients adopted to achieve

197 the normal compressive strength of concrete is listed in Table 3. The slump of concrete 198 mixture, which was mixed with a $10 \mathrm{~mm}$ maximum aggregate size, was $150 \mathrm{~mm}$. The 199 compressive strength of the concrete, which was determined according to the test of three 200 cylinders having a 150 diameter and a $200 \mathrm{~mm}$ height, was $37.6 \mathrm{MPa}$ at 28 days age. 
The process of pouring of concrete inside of the moulds was conducted as follows. Firstly, all moulds were cleaned and lubricated using a thin coating of mineral oil. Enough amount of concrete mixture was poured into the mould and distributed equally for making the required concrete cover. The poured concrete was lightly compacted using the table vibrator with a frequency of $50 \mathrm{~Hz}$. Then, the geogrid layer was put over the concrete cover at the specified

206 location. After that, more concrete was poured into the mould up to being filled, with the 207 compaction using a table vibrator. Finally, the surface of the poured concrete was carefully 208 levelled by the steel trowel. Fig. 9 shows the prism and slab moulds cast with the concrete.

\section{Testing of specimens}

In this study, the experimental tests conducted on the concrete specimens were achieved by

211 curing and drying these specimens within the controlled environmental conditions. Australian

212 Standards (AS) 1012.8.4 [23] was adopted to conduct these tests. All specimens were 213 assembled at the same location during the whole of the curing and drying time of the 214 specimens. This is to guarantee that all specimens would be exposed to the same 215 environmental conditions.

216 The process of curing was conducted during two main stages before the specimens were 217 dried. The first stage was performed by placing the specimens inside an environmentally 218 controlled chamber, with RH of $95 \%$ or more, as shown in Figure 10. This stage continued for 21924 hours from the casting of the specimens. The controlled chamber used in this stage was 220 installed with two humidifiers that release a water spray. This is to ensure that the percentage 221 of $\mathrm{RH}$ inside the chamber remained at $95 \%$ or more. To monitor the temperature and $\mathrm{RH}$ inside the chamber, two digital measuring devices were installed for this purpose. 
The second curing stage of the specimens started after 24 hours from the casting of the specimens. It was conducted by submerging the specimens in the water saturated with lime. This stage continued for six days with a temperature of $23 \pm 3^{\circ} \mathrm{C}$. Figure 11 shows the two containers that included the specimens and filled with lime saturated water.

A drying stage of the specimens, which is the stage that the specimens will start to dry and shrink, started after seven days from the casting of the specimens. At this stage, the specimens were placed in a drying chamber, within the temperature and $\mathrm{RH}$ of $23 \pm 3^{\circ} \mathrm{C}$ and $60 \pm 10 \%$, respectively. Fig. 12 shows the drying chamber.

The drying chamber, which is a fridge modified for this study to keep the temperature and RH within the required level, was installed with an air heater connected with a timer to keep the temperature at $23 \pm 3^{\circ} \mathrm{C}$. Also, an air fan having a $96 \mathrm{~mm}$ diameter was supplied to create air circulation around the specimens. A high accuracy sensor of RH was installed inside the drying chamber to measure the $\mathrm{RH}$ during the drying period. To further control the $\mathrm{RH}$, especially at the early age of concrete, one kilogram of silica gel particles was prepared and spread inside the drying chamber. This stage continued for 56 days from the casting of the specimens.

\section{Experimental results and discussion}

Nine concrete prisms and six of concrete slabs were tested by drying them in the controlled environmental conditions, at a temperature of $23 \pm 3^{\circ} \mathrm{C}$ and $\mathrm{RH}$ of $60 \pm 10 \%$.

The changes in the length, in one direction, of prisms and the changes in the area, in two directions, of slabs were measured over the drying time. Test readings of drying shrinkage of the specimens were collected at the total drying period of $7,14,21,28$, and 56 days. All results calculated herein were the average of five readings taken for each specimen for each 
246 group, which includes three specimens. These results were determined using the vertical 247 comparator device, as shown in Fig. 13.

248 The analysis and evaluation of test results were conducted through dividing the findings into 249 four intervals, which are: 7 to 14,14 to 21,21 to 28 , and 28 to 56 days. Fig. 14,15 and 16 and 250 Table 3 present a summary of the experimental results.

\subsection{Drying Shrinkage behaviour of prism specimens}

252 The drying shrinkage behaviour of Groups UP, GP20 and GP37.5 were analysed and 253 evaluated. Fig. 14 shows the average of drying shrinkage strains versus the intervals of drying 254 shrinkage.

255 At the first interval, 7 to 14 days, the drying shrinkage strains of Groups GP20 and GP37.5 256 were greater than Group UP by about $7 \%$ and $14 \%$, respectively. This is because the concrete 257 at this time still had a high percentage of porosities. These porosities, spread in the concrete 258 matrix, were still filled with the free water. This results in impairment of the bond between 259 the geogrid layer and the surrounding concrete. As a result, the role of the geogrid 260 reinforcement as a shrinkage restraining layer is lower. However, this situation is identical 261 with the behaviour of drying shrinkage of concrete pavements reinforced with fibre [1].

262 In the following intervals, the effect of geogrid on the shrinkage behaviour of Groups GP20 263 and GP37.5 started to be visible. This is because the concrete matrix started gaining their 264 appropriate hardness. It is due to progress in the process of the hydration of concrete. As a 265 result, the property of the bond between the geogrid layer and the concrete was increased. 
266 For intervals of 14 to 56 days, the drying shrinkage strains were reduced by about 3 to $15 \%$ 267 for Group GP20 and 7 to 17\% for Group GP37.5 in comparison with the reference (Group 268 UP).

269 From the same figure, Fig. 14, the drying shrinkage behaviour of Groups GP20 and GP37.5, 270 which differed in the locations of geogrid layer, was slightly different. For intervals of 7 to 14 271 and 14 to 21 days, the percentage of increase of the drying shrinkage strains of Group GP37.5 272 was $2 \%$ to $6 \%$ more than that of Group GP20. While, for the intervals of 21 to 28 and 28 to 27356 days, the percentage of increase of the shrinkage strains for Group GP20 was 1.2\% to 3\% more than that of Group GP37.5. This clearly reflects the influence of location of the geogrid layer in the concrete specimens, which should be located as nearly as possible to the surfaces 276 exposed to drying.

277 It should be noted that the results of drying shrinkage strains of the concrete specimens 278 reinforced with the geogrid were generally lower, when compared with the unreinforced 279 concrete specimens. It can say, this is because these specimens were dried within the 280 moderate environmental conditions, at a temperature of $23 \pm 3^{\circ} \mathrm{C}$ and $\mathrm{RH}$ of $60 \pm 10 \%$. These 281 conditions gradually have a low impact on the shrinkage behaviour of concrete specimens in 282 conjunction with the progress of hardening process of the concrete.

\subsection{Rate of drying shrinkage of the prism specimens}

284 The rate of drying shrinkage of concrete prism specimens can be defined, for this study, as the quantity measurement that aims to compare the average of drying shrinkage that occurred for

286 geogrid reinforced concrete specimens during the drying time compared to unreinforced 287 concrete specimens. 
Fig. 15 shows results of the rate of average drying shrinkage of Groups GP20 and GP37.5 compared to Group UP (reference) for each interval. In this figure, the rate of average drying shrinkage of Group UP was considered a fixed datum for comparison purposes and has a zero value. Thus, the negative sign means that the rate of average drying shrinkage of Groups GP20 and GP37.5 was greater than the reference. While the positive sign means that the rate of average drying shrinkage of Groups GP20 and GP37.5 was lower than the reference.

It can clearly be seen that, during the interval of 7 to 14 days, the rate of drying shrinkage of Groups GP20 and GP37.5 was achieved at a higher rate than the reference, about 0.0077 to $0.0147 \mathrm{~mm} /$ day, respectively. This illustrates that, when the concrete is still fresh, the geogrid reinforcement may contribute in increasing the rate of drying shrinkage of concrete. emphasises that the effect of geogrid reinforcement as the restraint of drying shrinkage starts when the concrete had an appropriate stiffness. While at the interval of 28 to 56 days, Groups GP20 and GP37.5 started to shrink at a slow rate because the specimens were dried within the moderate environmental conditions.

\subsection{Drying Shrinkage behaviour of slab specimens}

The average of drying shrinkage strains of the concrete slab specimens versus the intervals of

306 drying shrinkage are shown in Fig. 16. Although the slab specimens generally reflected the compatible shrinkage behaviour of concrete, the drying shrinkage strains at the interval of 14

308 to 21 were slightly different. 
309 However, the geogrid reinforcement proved that it has an impact in reducing the drying

310 shrinkage strains of concrete slab specimens reinforced with the geogrid (Group GS) by about

$3117 \%$ more than the reference (Group US). This is clearly demonstrated at the interval of 7 to 14

312 days. At the end of drying period, 28 to 56 days, the results of shrinkage strains of Groups US

313 and GS were nearly equal.

\section{7. Conclusions}

315 The drying shrinkage behaviour of concrete prism and slab specimens reinforced with the 316 biaxial geogrid layer was investigated. The specimens were dried within the controlled 317 environmental conditions, at a temperature of $23 \pm 3^{\circ} \mathrm{C}$ and $\mathrm{RH}$ of $60 \pm 10 \%$.

318 The changes in the length of the prisms and the changes in the area of the slab specimens

319 were measured and evaluated. According to the findings of the test, the principal conclusions 320 can be drawn as follow:

321 1. Except of the first drying interval, 7 to 14 days, the geogrid reinforcement could reduce the 322 drying shrinkage strains of the concrete prism specimens between $0.7 \%$ to $15 \%$ more than the 323 reference.

324 2. The geogrid reinforcement could decrease the drying shrinkage strains during the early age 325 of the specimens of Group G20. While, after 21 days of the casting, the geogrid layer in both 326 Groups GP20 and GP37.5 showed nearly the same effect.

327 3. The rate of drying shrinkage of Groups GP20 and GP37.5 declined by about $2 \%$ more than 328 the unreinforced specimens during the drying duration. 
4. For the concrete slab specimens, the geogrid reinforcement could reduce the shrinkage

330 strains by about 7 to $28 \%$ in comparison with the control specimens.

331 5. The concrete slab specimens were suggested in this study to simulate the behaviour of concrete pavements in providing a wide surface area exposed to the effect of environmental

333 conditions. However, more experimental studies are required before they are adopted.

\section{Acknowledgement}

335 The authors present special acknowledgements to senior technical officers Mr Alan Grant, $\mathrm{Mr}$

336 Richard Gasser, Mrs Ling (Linda) Tie and Mr Richard Berndt, and to all of the staff of the

337 High Bay Laboratory at the School of Civil, Mining, and Environmental Engineering at the

338 University of Wollongong, Australia. Also, the first author would like to thank the Ministry of

339 High Education and Scientific Research of Iraq and University of Wollongong for supporting

340 his PhD scholarship. 


\section{References}

[1] N. Jafarifar, K. Pilakoutas, T. Bennett, Moisture transport and drying shrinkage properties of steel-fibre-reinforced-concrete, Construction and Building Materials, 73 (2014) 41-50. [2] F. Pelisser, A.B.D.S.S. Neto, H.L.L. Rovere, R.C.D.A. Pinto, Effect of the addition of synthetic fibers to concrete thin slabs on plastic shrinkage cracking, Construction and Building Materials, 24 (2010) 2171-2176.

[3] R.E. Asbahan, J.M. Vandenbossche, Effects of Temperature and Moisture Gradients on Slab Deformation for Jointed Plain Concrete Pavements, Journal of Transportation Engineering, 137 (2011) 563-570.

[4] J. Zhang, D. Hou, Y. Han, Micromechanical modeling on autogenous and drying shrinkages of concrete, Construction and Building Materials, 29 (2011) 230-240.

[5] S. Kim, K. Gopalakrishnan, H. Ceylan, A simplified approach for predicting early-age concrete pavement deformation, J. Civ. Eng. Manage., 17 (2011) 27-35.

[6] J. Zhang, H. Dongwei, S. Wei, Experimental study on the relationship between shrinkage and interior humidity of concrete at early age, Mag Concr Res, 62 (2010) 191-199.

[7] Y. Shao, A. Mirmiran, Control of Plastic Shrinkage Cracking of Concrete with Carbon Fiber-Reinforced Polymer Grids, J. Mater. Civ. Eng., 19 (2007) 441-444.

[8] Z. Ahmad, A. Ibrahim, P. Tahir, Drying shrinkage characteristics of concrete reinforced with oil palm trunk fiber, International Journal of Elegancy Science and Technology, 2 (2010) 1441-1550.

[9] D.P. Bentz, W.J. Weiss, Internal Curing: A 2010 State-of-the-Art Review, National Institute of Standards and Technology [NIST], (2011).

[10] E. Güneyisi, M. Gesoğlu, A. Mohamadameen, R. Alzeebaree, Z. Algın, K. Mermerdaş, Enhancement of shrinkage behavior of lightweight aggregate concretes by shrinkage reducing admixture and fiber reinforcement, Construction and Building Materials, 54 (2014) 91-98. 
[11] Y. Wei, W. Guo, X. Zheng, Integrated Shrinkage, Relative Humidity, Strength

Development, and Cracking Potential of Internally Cured Concrete Exposed to Different

Drying Conditions, Drying Technology, (2015) 1-37.

[12] K. Kim, S. Chun, Evaluation of Internally Cured Concrete Pavement Using

Environmental Responses and Critical Stress Analysis, Ind. J. Concr. Struct. Mater., 9 (2015) 463-473.

[13] A.M. Ghaly, Flexural performance of rubberized concrete panels reinforced with polymer grid, J. Green Build., 1 (2006) 101-117.

[14] F.E. Meski, G.R. Chehab, Flexural behavior of concrete beams reinforced with different types of geogrids, J. Mater. Civ. Eng., 26 (2014).

[15] A. Arulrajah, M.A. Rahman, Evaluation of interface shear strength properties of geogridreinforced construction and demolition materials using a modified large-scale direct shear testing apparatus, J. Piratheepan, M.W. Bo, M.A. Imteaz, J. Mater. Civ. Eng., 26 (2014) 974982.

[16] R. Siva Chidambaram, P. Agarwal, The confining effect of geo-grid on the mechanical properties of concrete specimens with steel fiber under compression and flexure, Construction and Building Materials, 71 (2014) 628-637.

[17] R. Siva Chidambaram, P. Agarwal, Flexural and shear behavior of geo-grid confined RC beams with steel fiber reinforced concrete, Construction and Building Materials, 78 (2015) $271-280$

[18] R. Siva Chidambaram, P. Agarwal, Inelastic behaviour of RC beams with steel fibre and polymer grid confinement, Indian Concr J, 89 (2015) 83-90.

[19] W. Wang, M.N. Sheikh, M.N.S. Hadi, Axial compressive behaviour of concrete confined with polymer grid, Materials and Structures, (2015) 1-17.

[20] X. Tang, G.R. Chehab, S. Kim, Laboratory study of geogrid reinforcement in Portland 
cement concrete, 6th RILEM International Conference on Cracking in Pavements, Chicago, IL, (2008) 769-778.

[21] S. Maxwell, W. KIM, T.B. EDIL, C.H. Benson, Effectiveness of geosynthetics in stabilizing soft subgrades, Final Rep. No. 0092-45-15, Dept. of Civil and Environmental Engineering, Univ. of Wisconsin-Madison, Madison, ( 2005).

[22] ASTM D6637-15, Standard test method for determining tensile properties of geogrids by the single or multi-rib tensile method, American Society for Testing and Materials, West Conshohocken, PA, USA, (2015).

[23] AS 1012.8.4-2015, Methods of testing concrete; Method 8.4: Method for making and curing concrete-drying shrinkage specimens prepared in the field or in the laboratory, Standards Australia, Sydney, Australia, ( 2015).

[24] AS 1012.13-2015, Methods of testing concrete; Method 13: Determination of the drying shrinkage of concrete for samples prepared in the field or in the laboratory, Standards Australia, Sydney, Australia, (2015).

[25] Y. Qin, J.E. Hiller, Modeling the temperature and stress distributions in rigid pavements: Impact of Solar Radiation absorption and heat history development, KSCE Journal of Civil Engineering, 15 (2011) 1361-1371.

[26] Hanson Australia Pty Ltd, Ready Mix Concrete Supplier, Australia, Sydney, Picton (NSW)2571, 2017, <http://www.hanson.com.au>

[27] Grace Construction Products and Darex Packing Technologies, GCP Applied Technologies, Issues of Construction Products, Australia, Brisbane, 2016, <file:///E:/Suggest\%20reading/Shrinkage\%20file/WRDA\%20PN20\%20adimeture.pdf> 


\section{List of Figures}

\section{Fig. 1. Biaxial geogrid}

352 Fig. 2. Tensile test of single biaxial geogrid sample. (a) Fixing the biaxial geogrid sample by

353 clamps with testing machine. (b) Measuring the initial gauge length. (c) Rupture failure of

354 biaxial geogrid sample

355 Fig. 3. Tensile strength versus strain of biaxial geogrid samples

356 Fig. 4. Configurations of concrete prism specimens. (a) Unreinforced concrete prism 357 specimens (UP). (b) Geogrid reinforced concrete prism specimens (GP20). (c) Geogrid 358 reinforced concrete prism specimens (GP37.5)

359 Fig. 5. Configurations of concrete slab specimens reinforced with geogrid (GS)

360 Fig. 6. Standard steel prism moulds

361 Fig. 7. Preparation of timber slab moulds. (a) Walls of slab moulds. (b) Fixing the walls with 362 the base of slab moulds. (c) Slab moulds

363 Fig. 8. Biaxial geogrid layer inside the moulds. (a) For concrete prism specimens. (b) For 364 concrete slab specimens

365 Fig. 9. Casting of concrete prism and slab specimens

366 Fig. 10. Initial curing environmental chamber of concrete specimens

367 Fig. 11. Containers of concrete specimens utilised at the standard moist curing stage

368 Fig. 12. Modified drying chamber. (a) Front view of the modified drying chamber. (b)

369 Specimens inside the modified drying chamber. (c) Environmental control tools

370 Fig. 13. Vertical comparator device

371 Fig. 14. Average of drying shrinkage strains versus intervals of readings for unreinforced and geogrid reinforced concrete prism specimens

373 Fig. 15. Rate of drying shrinkage of unreinforced and geogrid reinforced concrete prism

374 specimens 
375 Fig. 16. Average of drying shrinkage strains versus intervals of readings for unreinforced and

376 geogrid reinforced concrete slab specimens

377

378

379

380

381

382

383

384

385

386

387

388

389

390 
$391 \quad$ List of Tables

392 Table 1. Physical and mechanical properties of biaxial geogrid samples

393 Table 2. Test matrix of experimental study

394 Table 3. Mixture proportion of concrete [27]

395 Table 4. Drying shrinkage test results

396

397

398

399

400

401

402

403

404

405

406

407 
Table 1. Physical and mechanical properties of biaxial geogrid samples.

Test measurements

\begin{tabular}{|c|c|c|c|c|}
\hline \multicolumn{5}{|c|}{ Biaxial geogrid samples } \\
\hline 1 & 2 & 3 & 4 & 5 \\
\hline \multicolumn{5}{|c|}{ Biaxial geogrid } \\
\hline \multicolumn{5}{|c|}{$38 \times 38$} \\
\hline \multicolumn{5}{|c|}{2.0} \\
\hline \multicolumn{5}{|c|}{3.0} \\
\hline \multicolumn{5}{|c|}{4.0} \\
\hline 197 & 203 & 197 & 197 & 197 \\
\hline 1222 & 1467 & 1322 & 1258 & 1436 \\
\hline 57 & 109 & 79 & 64 & 96 \\
\hline 29 & 54 & 40 & 32 & 49 \\
\hline \multicolumn{5}{|c|}{1341} \\
\hline \multicolumn{5}{|c|}{81} \\
\hline \multicolumn{5}{|c|}{96.52} \\
\hline
\end{tabular}

409

Geosynthetic products

Rib pitch (mm)

MidRib depth (mm)

MidRib width (mm)

Nodal thickness (mm)

Initial gauge length of sample (mm)

Tensile strength of sample (N)

Elongation of sample (mm)

Percentage increase of elongation (\%)

Average of tensile strength of samples (N)

Average of elongation of samples (mm)

96.52

Standard deviation of the results of tensile strength $(\mathrm{N})$

410

411

412

413

414

415

416

417

418

419

420

421

422

423

424

425

426

427

428

429

430

431

432

433 
Table 2. Test matrix of experimental study.

\begin{tabular}{|c|c|c|c|c|c|c|}
\hline $\begin{array}{l}\text { Specimens } \\
\text { group }\end{array}$ & $\begin{array}{l}\text { Specime } \\
\mathrm{n} \text { Label }\end{array}$ & $\begin{array}{l}\text { Number of } \\
\text { specimens }\end{array}$ & $\begin{array}{l}\text { Specimen size } \\
(\mathrm{mm})\end{array}$ & $\begin{array}{l}\text { Reinforcement } \\
\text { condition }\end{array}$ & $\begin{array}{l}\text { Reinforcement } \\
\text { material }\end{array}$ & $\begin{array}{l}\text { Location }^{\mathrm{a}} \text { of } \\
\text { geogrid }(\mathrm{mm})\end{array}$ \\
\hline \multirow{3}{*}{ Prism group } & UP & 3 & \multirow{3}{*}{$75 \times 75 \times 280$} & Unreinforced & ------- & ------ \\
\hline & GP20 & 3 & & Reinforced & Biaxial geogrid & 20 \\
\hline & GP37.5 & 3 & & Reinforced & Biaxial geogrid & 37.5 \\
\hline \multirow[b]{2}{*}{ Slab group } & US & 3 & \multirow[b]{2}{*}{$30 \times 280 \times 280$} & Unreinforced & ------- & -------- \\
\hline & GS & 3 & & Reinforced & Biaxial geogrid & 15 \\
\hline
\end{tabular}

${ }_{a}$ : The location of biaxial geogrid layer from the top of specimen.

435

436

437

438

439

440

441

442

443

444

445

446

447

448

449

450

451

452

453

454

455

456

457

458

459

460 
Table 3. Mixture proportion of concrete [27].

\begin{tabular}{c|c|c|c|c|c|c|c|c}
\hline $\begin{array}{c}\text { Concrete } \\
\text { ingredients }\end{array}$ & $\begin{array}{c}\text { Cement } \\
\left(\mathrm{kg} / \mathrm{m}^{3}\right) \\
\text { general } \\
\text { purpose } \\
\text { type }\end{array}$ & $\begin{array}{c}\text { Fly ash } \\
\left(\mathrm{kg} / \mathrm{m}^{3}\right)\end{array}$ & $\begin{array}{c}\text { Slag } \\
\left(\mathrm{kg} / \mathrm{m}^{3}\right)\end{array}$ & $\begin{array}{c}\text { Sand } \\
\left(\mathrm{kg} / \mathrm{m}^{3}\right)\end{array}$ & $\begin{array}{c}\text { Fine Sand } \\
\left(\mathrm{kg} / \mathrm{m}^{3}\right)\end{array}$ & $\begin{array}{c}\text { Coarse } \\
\text { aggregate } \\
(10 \mathrm{~mm} \text { size }) \\
\left(\mathrm{kg} / \mathrm{m}^{3}\right)\end{array}$ & $\begin{array}{c}\text { Water } \\
\text { reducing } \\
\text { admixture- } \\
\mathrm{PN} 20^{*}\left(\mathrm{ml} / \mathrm{m}^{3}\right)\end{array}$ & $\begin{array}{c}\text { Water } \\
\left(\mathrm{Litter} / \mathrm{m}^{3}\right)\end{array}$ \\
\hline Dosage & 164.05 & 65.62 & 98.43 & 339.69 & 687.79 & 829.13 & 1476 & 132.09 \\
\hline
\end{tabular}

${ }^{*}$ Admixture-PN20 is an aqueous solution of polycarboxylate polymers and hydrocarbons [27].

462

463

464

465

466

467

468

469

470

471

472

473

474

475

476

477

478

479

480

481

482

483

484

485

486

487

488

489

490

491 
Table 4. Drying shrinkage test results.

\section{Concrete prism specimens}

\begin{tabular}{|c|c|c|c|c|c|c|c|c|c|}
\hline \multicolumn{10}{|c|}{ Concrete prism specimens } \\
\hline \multirow{3}{*}{ Group label } & \multicolumn{5}{|c|}{ Age of drying time (days) } & \multicolumn{4}{|c|}{ Intervals of drying shrinkage readings (days) } \\
\hline & 7 & 14 & 21 & 28 & 56 & 7 to 14 & 14 to 21 & 21 to 28 & 28 to 56 \\
\hline & \multicolumn{5}{|c|}{ Average of readings of drying shrinkage $(\mathrm{mm})$} & \multicolumn{4}{|c|}{ Average of shrinkage strains $\left(10^{-6}\right)(\mathrm{mm} / \mathrm{mm})$} \\
\hline UP & 6.873 & 6.142 & 5.861 & 5.806 & 6.218 & 2926 & 1124 & 221 & 1648 \\
\hline GP20 & 7.371 & 6.585 & 6.312 & 6.265 & 6.674 & 3142 & 1094 & 188 & 1636 \\
\hline GP37.5 & 7.293 & 6.458 & 6.179 & 6.134 & 6.538 & 3337 & 1117 & 182 & 1616 \\
\hline \multicolumn{10}{|c|}{ Concrete slab specimens } \\
\hline \multirow{3}{*}{ Group label } & \multicolumn{5}{|c|}{ Age of drying time (days) } & \multicolumn{4}{|c|}{ Intervals of drying shrinkage readings (days) } \\
\hline & 7 & 14 & 21 & 28 & 56 & 7 to 14 & 14 to 21 & 21 to 28 & 28 to 56 \\
\hline & \multicolumn{5}{|c|}{$\begin{array}{l}\text { Average of readings of drying shrinkage in the } \\
\text { two directions ( } \mathrm{mm})\end{array}$} & \multicolumn{4}{|c|}{$\begin{array}{l}\text { Average of shrinkage strains in the two } \\
\text { directions }\left(10^{-6}\right)(\mathrm{mm} / \mathrm{mm})\end{array}$} \\
\hline US & 7.111 & 6.373 & 6.165 & 6.137 & 6.514 & 2949 & 834 & 112 & 1508 \\
\hline GS & 6.910 & 6.222 & 5.923 & 5.902 & 6.282 & 2748 & 1197 & 80 & 1520 \\
\hline
\end{tabular}

493 